\title{
What is the evidence that invasive species are a significant contributor to the decline or loss of threatened species? A systematic review map
}

\author{
Philip D Roberts ${ }^{1 *}$, Hilda Diaz-Soltero ${ }^{2}$, David J Hemming ${ }^{1}$, Martin J Parr ${ }^{1}$, Nicola H Wakefield ${ }^{1}$ and Holly J Wright ${ }^{1}$
}

\begin{abstract}
Background: Invasive species have been reported as one of the leading causes of species extinction. However, the evidence to support or contest their effects on the decline and/or extinction of threatened species has been largely unavailable and few efforts have been made to collate such information. In order to develop national and international policies addressing the loss of threatened species, and to prioritise research and mitigation efforts, the evidence needs to be systematically reviewed and mapped to determine the importance of such effects.

Methods/design: The searching of online publication databases, grey literature and other resources, such as recovery plans of endangered species, aims to gather existing evidence on whether invasive species are a significant contributor to the decline and/or extinction of threatened species. This study focuses on US species under threat. The methods used to carry out the systematic review will address the following two fundamental questions: (a) what proportion of threatened species have an invasive species as a significant contributor to their decline and (b) through what mechanisms do invasive species contribute towards the decline of native species? The pool of resources gathered will be analysed for relevance and quality using a pre-defined scoring system. A systematic map will be produced, summarising information from individual studies. Where possible, data will be extracted from included studies and synthesised using meta-analysis.
\end{abstract}

Keywords: Invasive species, Alien species, Threatened species, Impact, Decline, Extinction, Mechanism

\section{Background}

There is a broad scientific consensus that invasive species are likely to play a crucial and devastating role in species extinction. At the 2010 Convention on Biological Diversity Conference of Parties (COP10) it was stated that:

"Invasive species are the second biggest driving force of species extinction, after the effects of human activity (habitat loss, overexploitation, and pollution)."

This extinction process seems likely to accelerate, with climate change acting as one of its driving factors, as it may expand the ranges of many invasive species.

However, while there are good ecological reasons for expecting that invasive species are playing a central role

\footnotetext{
*Correspondence: phildroberts@gmail.com

'CABI, Nosworthy Way, Wallingford, Oxfordshire, United Kingdom

Full list of author information is available at the end of the article
}

in the loss of native species, the evidence to support or contest that idea has not been collected or examined systematically at either a national or international level, and even the evidence source behind the COP10 statement has not been cited. For example, within the United States (USA), an internal audit of the Species Recovery Plans of candidate species for IUCN Threatened Species List, undertaken by USDA National Invasive Species Council and US Fisheries and Wildlife Service (FWS) in 2010-11, found that the information regarding invasive species that may cause the decline or extinction of threatened species is held in thousands of separate, unobtainable statements about individual species that is held in the filing cabinets of site/species experts or in disparate datasets that they manage on local machines, even though the main resource for invasive species policy and evidence is publically available (http://www.invasivespeciesinfo.gov/). Therefore, the evidence that underpins the Species Recovery Plans is either underreported observational or 
expert opinions that are not readily accessible to the scientific community. Wider than this, it is the experience of the review team that within the introductions of published literature the impact to a native species by an invasive, at a particular location, is often inferred, when this is not the focus of that particular paper. These unsubstantiated statements may be used as evidence in state/country/global recovery plans that it is the invasive that is the major causative agent for the decline of the native, when other factors, (i.e. change in grazing regimes/pollution etc.) may in fact be responsible for the native species' decline. Taking these elements together means that it is impossible to determine the true extent to which invasive species are impacting biodiversity from the current unreviewed evidence base. It is vital to have an answer to this central question in order to develop national and international polices to address the loss of threatened species, and to prioritise research and mitigation efforts.

Previous efforts to review the evidence have focused on a limited subset of species, such as a single taxonomic Kingdom or Order and have led to disagreements within the peer-reviewed literature. For example, Clavero and García-Berthou's [1] editorial on invasive species causing animal extinctions argued that the use of different methodologies for reporting and sourcing information had led to drastically differing conclusions to whether invasive species caused extinctions to either IUCN Red Listed Threatened Species [2] or those threatened within countries, e.g. North American fish species [3], or mammals on Australian islands [4]. Therefore, this study aims to systematically map the evidence for all US listed endangered and threatened species on the US FWS list and candidate threatened species awaiting listing, that are being impacted by an invasive species, and by what mechanism this impact is achieved. Under the US Endangered Species Act, "endangered" means "any species which is in danger of extinction throughout all or a significant portion of its range", while "threatened" is defined as "any species which is likely to become an endangered species within the foreseeable future throughout all or a significant portion of its range". Candidate species are under consideration for threatened or endangered status. The study is focused on species listed for the USA because scoping work indicated that the full IUCN list of 3,947 critically endangered species would require more resources than were available. The US FWS list includes $65 \%$ of the species on the IUCN $\mathrm{CR}$ list for the USA. The evidence in the literature from all taxa will be included, but there will be no attempt to balance numbers from different taxa.

The output of this study will allow the USDA and US FWS to base both Species Recovery Plans and candidate species listing nominations on the best available evidence. In addition, the evidence will be used to inform on invasive species that should be on alert lists to land managers.

\section{Objective of review}

The primary review question is: "What is the evidence that invasive species are a significant contributor to the decline or loss of US threatened species?"

To answer this main question, a group of stakeholders, at the request of the USDA, took part in a two-day meeting in Georgetown, Washington D.C., USA, to discuss invasive species and their impact in North America. The broadly based stakeholder group consisted of USDA National Invasive Species Council, The Conservation Breeding Specialist Group (CBSG) of IUCN, US FWS, the National Marine Fisheries Service (NMFS) and the review team from CABI. The group was selected to represent US stakeholders, international conservation and an independent science organisation with a specialist focus on control of invasive species. Despite their different perspectives, all stakeholders were in agreement that in order to answer such a broad main question, two sub questions (see Table 1) that would capture an impact (or any measure of change) to the threatened species and also the mechanisms by which the invasive species causes that impact would need to be investigated.

Secondary question 1: "What proportion of threatened species have an invasive species as a significant contributor to their decline?"

This question will include an analysis of the USA threatened species from the US FWS list and candidate species lists (under consideration for US FWS threatened status level). This question will map all evidence relating to both the invasive species and the threatened species, effectively coming up with species pairs (for

Table 1 Components of the systematic review subquestions (SQ)

\begin{tabular}{|c|c|c|c|c|}
\hline & Population & $\begin{array}{l}\text { Intervention/ } \\
\text { exposure }\end{array}$ & $\begin{array}{l}\text { Comparator/ } \\
\text { study design/ } \\
\text { evidence type }\end{array}$ & Outcome \\
\hline SQ1 & $\begin{array}{l}\text { Threatened } \\
\text { species: US } \\
\text { FWS listed } \\
\text { Endangered, } \\
\text { Threatened } \\
\text { and } \\
\text { Candidate } \\
\text { species }\end{array}$ & $\begin{array}{l}\text { Invasive } \\
\text { species }\end{array}$ & $\begin{array}{l}\text { No invasive } \\
\text { species: } \\
\text { randomised } \\
\text { block design } \\
\text { time series } \\
\text { (before and } \\
\text { after); Site } \\
\text { comparison } \\
\text { (comparing } \\
\text { exposure to } \\
\text { non-exposure } \\
\text { on adjacent } \\
\text { sites); } \\
\text { Observations }\end{array}$ & $\begin{array}{l}\text { Change in } \\
\text { status of the } \\
\text { Threatened } \\
\text { species } \\
\text { population size } \\
\text { (size/range/ } \\
\text { density/ } \\
\text { fecundity etc.) }\end{array}$ \\
\hline SQ2 & $\begin{array}{l}\text { Invasive } \\
\text { species }\end{array}$ & $\begin{array}{l}\text { Threatened } \\
\text { species: US } \\
\text { FWS listed } \\
\text { Endangered, } \\
\text { Threatened } \\
\text { and } \\
\text { Candidate } \\
\text { species }\end{array}$ & $\begin{array}{l}\text { Biological } \\
\text { papers, } \\
\text { laboratory } \\
\text { studies, } \\
\text { genetic studies }\end{array}$ & $\begin{array}{l}\text { Mechanism by } \\
\text { which the } \\
\text { invasive species } \\
\text { has competitive } \\
\text { advantage over } \\
\text { other species }\end{array}$ \\
\hline
\end{tabular}


each specific invasive species and its relevant threatened species), and the impact that the invasive species has being analysed. From these individual pairs, an overall proportion of impact will be calculated.

Secondary question 2: "Through what mechanisms do invasive species contribute towards the decline of native species?"

This question will identify the mechanisms by which each of the invasive species identified in the previous question impact the native species. All the data relating to mechanisms presented in the evidence selected will be captured through the process and summarise under relevant mechanistic categories.

In addition, the review team will also highlight all the different impact scales that are available to managers and policy makers.

The essence of this approach uses the conventional population, exposure, comparator, outcome (PECO) structure, where the population is the native threatened species, the exposure is the introduction or presence of the population of the invasive species, the comparator is a measure within the study design, such as the population before the arrival of the invasive species, or a comparable population not exposed to the invasive species, and the outcome is the change in the population of the native threatened species (this may include change in distribution, abundance, density or other dynamics).

\section{Methods}

\section{Search strategy}

The following general electronic databases will be searched:

1. CAB Abstracts (through CAB Direct)

2. Web of Knowledge

3. British Library Direct

4. Science Direct

5. Directory of Open-Access Journals

6. COPAC

7. Scirus (All journal sources)

8. Scopus

9. Agricola

10. Centre for Ecology and Hydrology online database

11. JSTOR

12. ConservationEvidence.com

13. WorldWideScience.org

14. Wildlife and Ecology Studies Worldwide

The US Threatened Species Recovery Plans will also be consulted in detail. These are USA-specific plans that are known to contain references to invasive species in relation to the threatened species in question. Further references will be obtained from Smithsonian's Biological Conservation Newsletter and from four reports (March, June, Sept and Dec 2011) by Dr Jan Eldridge on invasive species threatening endangered, threatened and candidate species for the CBSG on the IUCN website.

Other specific/specialised databases will be searched as appropriate where identified or recommended by experts within the field, e.g.:

1. CABI's Invasive Species Compendium (open-access)

2. IUCN Red List of Threatened Species data

3. US Fish and Wildlife Service

4. USDA National Invasive Species Information Centre

The following resources will be examined for relevant information on invasive species and an assessment made as to whether they will contribute significant extra information pertinent to the systematic review questions that is not available in the primary resources consulted:

1. Nonindigenous Aquatic Species

2. Global Invasive Species Database

3. Pacific Island Ecosystems at Risk (PIER)

These sources will be the basis of the lists of invasive species and threatened species considered and actively sought in the systematic review. Use of specialised databases that require name-specific searches will be determined according to time capabilities. The emphasis will be on a representative, repeatable and unbiased approach that allows the clearest possible answer to the sub question.

Hand searching of key titles will also be undertaken, e.g.:

\section{Aliens, a publication by IUCN}

Recognised experts, practitioners and recent authors will be contacted to see if any relevant unpublished material or datasets are available for inclusion within the review.

In addition, web searches will be performed using the search engines:

Google Scholar, Microsoft Academic Search and Google (organic). The first 50 hits (.doc(x)/.txt/.xls/.pdf files, using advanced search) from each data source will be examined for appropriate evidence. No further links from the captured website will be followed unless to a doc/. pdf file.

Email lists will be joined (CABI's Invasive Alien Species List, Science Daily and The IUCN Aliens List) to ensure relevant references published following the initial literature will be incorporated into the study. All emerging new literature will be logged in a separate EndNote library to allow for transparency of when and how all references entered the review process.

The list of search terms to be used is listed in the Appendix. The most effective search strategy will be 


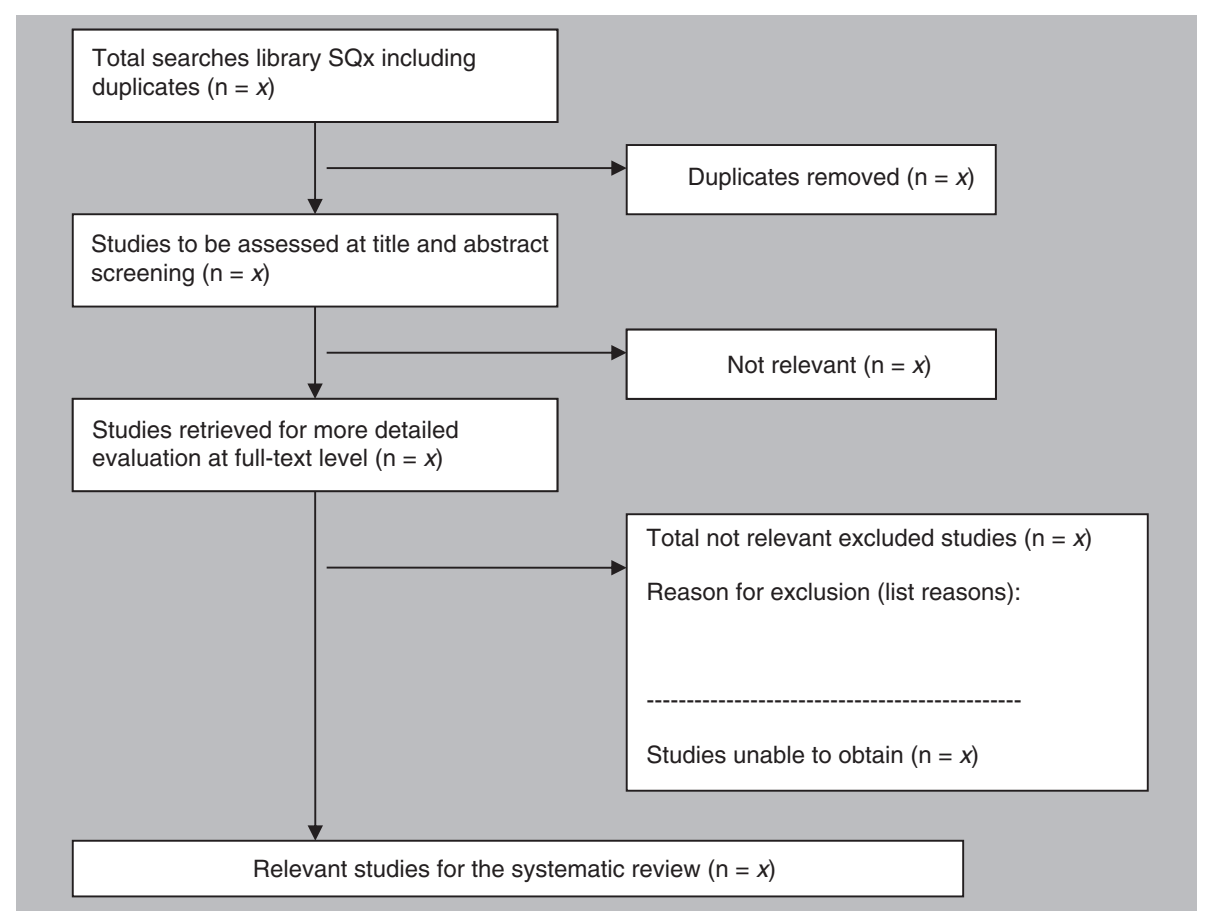

Figure 1 Literature assessment flow through the search and screening process. Values $(n=x)$ are the number of studies at each stage, $x$ to be replaced by the actual number in the systematic review report. (Based on QUOROM statement flow diagram) [5].

developed through small-scale scoping trials, using some of the species about which greatest concern has been raised. It is envisaged that extensive lists of full species names of potential invasive species and threatened species will need to be combined in Boolean searches to find the relevant material.

Each search will be stored in a separate EndNote Library, for record keeping and then combined into a "Total searches library SQ $x$ (including duplications)". Two de-duplication processes will be undertaken, firstly using EndNote, then a second manual scan to remove duplicates with differing syntax (e.g. '2' or 'II'). This deduplication process will create the first EndNote Library, which would be considered for applying the study inclusion criteria to at the title and abstract level (see Figure 1). As each of the secondary questions has a different search strategy to capture the potential body of evidence this process will be undertaken separately for each of the questions.

\section{Study inclusion}

The inclusion and exclusion criteria will be applied by one reviewer to all potential studies at the title and abstract level. Where there is insufficient information to make an informed decision regarding a studies inclusion, then relevance to the next stage of the review process (full-text assessment) will be assumed. A second reviewer will examine a random subset of at least $25 \%$ of the reference list (up to a maximum of 2,500 references) to assess repeatability of the selection criteria. Kappa analysis will be performed, with a rating of substantial being required to pass the assessment. Disagreement regarding inclusion/exclusion of studies will be resolved by consensus, or following assessment by a third reviewer. If the Kappa value is low, the reference list will be reassessed against adjusted inclusion and exclusion criteria. The same subset of references will be reassessed by a second reviewer with Kappa analysis. Reviewers will then consider articles viewed at the full-text level for relevance, either excluding them from, or admitting them to, the review.

For secondary question 1, studies will be assessed against the following inclusion/exclusion criteria:

\section{Population}

All studies that investigate one or more species that are included on the US FWS list as Endangered, Threatened or Candidate species list. These are listed in Appendix.

\section{Exposure}

Any invasive species having a documented impact (positive, negative or lack of) on the threatened species.

\section{Comparator(s)}

$\mathrm{n} / \mathrm{a}$ (although for inclusion in analysis a comparator of no invasive species or a time series will be required). 


\section{Study Design}

All study designs will to be included in the review. The quality of the original methodology for each study will be assessed and summarised in the final report.

For secondary question 2 studies will be assessed against the following inclusion/exclusion criteria:

\section{Population}

Any invasive species that has been identified under secondary question 1.

\section{Exposure}

The invasive species has had an impact on a threatened species under secondary question 1 .

\section{Comparator(s)}

$\mathrm{n} / \mathrm{a}$

\section{Study Design}

All study designs will be accepted into the review.

\section{Focus of Study}

The study must mention one or more mechanisms by which the invasive species impacts on the threatened species.

\section{Exclusion for both sub questions:}

a) Owing to the time constraints of the review, only English language documents will be included within the final synthesis. Any non-English documents will be identified in a separate EndNote library, which will be made available to future review teams.

b) Human pathogens are excluded from this review as an invasive species type.

For both the sub questions the definition of 'Invasive Species' as defined by the USA Executive Order 13112 of February 3, 1999 is being used. It states that an "Alien species" means, with respect to a particular ecosystem, any species, including its seeds, eggs, spores, or other biological material capable of propagating that species, that is not native to that ecosystem. It also states that "Invasive species" means an alien species whose introduction does or is likely to cause economic or environmental harm or harm to human health. Harm to animal health has been added to that definition, using the World Organisation for Animal Health (OIE) definitions as to what is meant by "harm". Threatened species includes those species that are both US state or nationally registered and those US candidate species under consideration that do not appear in the IUCN Red list.

For this Systematic Review Map, work will focus on invasive species whose establishment and spread threaten ecosystems and habitat or species [6]. For inclusion into the review, there needs to be a documented impact to a species that the USA listed on the US FWS Endangered, Threatened or Candidate species lists.

\section{Potential effect modifiers and reasons for heterogeneity}

Where information regarding the reasons for heterogeneity is presented in the studies, it will be recorded, and when possible assessed. Sources of heterogeneity within the studies may be one (or more) of the following: study design, habitat type/degradation/alteration, geographical region of USA, species taxonomic position (e.g. mammal or plant), lifehistory strategy of either species and trophic level.

\section{Study quality assessment}

For secondary question 1, the review team will assess the study methodologies reported in all articles accepted at the full-text level. The study quality will be scored according to a hierarchy of evidence adapted from systematic review guidelines used in medicine and public health [7] and conservation [8]; e.g. a randomised control trial would be weighed higher than a site comparison study (see Appendix for the draft coding tool).

The results of the study quality assessments will be presented in summary tables within the full review document, for full transparency.

For secondary question 2, the study type (laboratory, field, etc.) will be recorded for summary in the full review, but no formal assessment of quality will be undertaken.

\section{Data extraction strategy}

Data will be extracted by one reviewer, and a random subset of at least $25 \%$ of the selected studies will be checked by another reviewer to verify repeatability and accuracy. The electronic data extraction form will be trialled and checked with the question stakeholders. All data extracted will be presented in summary tables in the full review document.

For secondary question 1, data regarding the study characteristics (e.g. location), study methodology (e.g. timeline and sample size), the threatened species, invasive species (and whether the invasive population increases over the time of the study), and the impact will be recorded. For secondary question 2, data relating to the mechanisms used by the invasive species to impact on the threatened species will be extracted. 


\section{Data mapping and synthesis}

As data synthesis may not be possible for accepted studies, summary tables and a systematic map will be produced. The map will follow the format of a searchable database, summarising study characteristics, study quality and results. This will be organised using transparent, replicable criteria for ease of updating.

Quantitative analysis will be undertaken on any data suitable for formal statistical analysis. Where possible, meta-analysis for each of the interventions will be carried out with reasons for heterogeneity assessed by meta-regression (univariate or multivariate). Subset analysis will be undertaken if there is sufficient data on taxonomic groups or specific habitats (highlighting across-species heterogeneity). If at all possible data will be captured across multiple isolated populations (e.g. mountain tops) that might allow for within species heterogeneity to be investigated.

It is envisaged that species pairs will be created between a threatened species and an invasive species. These species pairs will allow both impact and competition mechanism to be categorised against them, to produce an overall systematic visualisation of the status of invasive/threatened species relationships.
Publication bias will be assessed, although it is envisaged that this will be reduced by accepting all publication types (formal peer-reviewed journal articles through reports and species plans to observational reports), and evidence of both negative and positive relationships between threatened species and invasive species. In addition the review team's level of agreement at all stages will be assessed.

\section{Appendix one: search terms used on databases Secondary question 1}

Search for all databases:

1. ("Invasive species" OR "Invasive alien species" OR "IAS" OR feral) AND ("threatened species" OR "endangered species" OR "candidate species")

2. ("Invasive species" OR "Invasive alien species" OR "IAS") AND (reduction OR decline OR extinction)

3. Species list (the scientific names of all US FWS Endangered, Threatened and Candidate species as listed September 2011.)

\section{Appendix two}

Table 2 shows draft quality coding tool.

Table 2 Draft quality coding tool

\begin{tabular}{|c|c|c|c|}
\hline Generic data quality features & Specific data quality features & Quality element & Quality score \\
\hline \multirow[t]{5}{*}{ Internal validity of study } & $\mathrm{N} / \mathrm{A}$ & Clear aims & 2 \\
\hline & & $\begin{array}{l}\text { Treatment and control groups similar at start of trial } \\
\text { (low heterogeneity between locations, size of exp. } \\
\text { areas, soil type, shading, plant types etc.) }\end{array}$ & 2 \\
\hline & & Outcomes measured accurately and reliably & 2 \\
\hline & & Control of confounding variables & 2 \\
\hline & & Replications of study & 2 \\
\hline \multirow[t]{6}{*}{ Study Design } & N/A & $\begin{array}{l}\text { Randomised block design time series } \\
\text { (pre-intervention data/observations) }\end{array}$ & 80 \\
\hline & & Non-randomised block design time series & 60 \\
\hline & & $\begin{array}{l}\text { Historical dataset e.g. > } 10 \text { years } \\
\text { (not from current experimental observation) }\end{array}$ & 50 \\
\hline & & Data without comparator & 30 \\
\hline & & Descriptive, field observations & 20 \\
\hline & & Expert opinion & 10 \\
\hline \multirow[t]{2}{*}{ Measurement of outcomes } & $\begin{array}{l}\text { Quantitative } \\
\text { measurements } \\
\text { of intervention }\end{array}$ & $\begin{array}{l}\text { Population size, range, density, fecundity-pop. } \\
\text { counts/mark-recapture/nest counts/dropping counts }\end{array}$ & 10 \\
\hline & $\begin{array}{l}\text { Qualitative/descriptive } \\
\text { observations of intervention } \\
\text { (e.g. vague estimate of time } \\
\text { since introduction) }\end{array}$ & Population size, range, density, fecundity & 5 \\
\hline
\end{tabular}




\section{Competing interests}

The authors declare that they have no competing interests.

\section{Authors' contributions}

PR conceived of the study, coordinated development of the protocol and drafted the manuscript. HD, DH, MP, NW and HW participated in development of the protocol and drafting of the manuscript. All authors read and approved the final manuscript.

\section{Funding disclosure}

This proposal is submitted as a partnership between CABI, the National Marine Fisheries Service (NMFS), CBSG/IUCN and USDA's Invasive Species Coordination Program. The funding for this review comes from the USDA Invasive Species Coordination Program, managed by Ms. Hilda Diaz-Soltero, USDA Senior Invasive Species Coordinator, who is an advisor to the review team but not taking an active role in any phase of the selection and reviewing of the evidence captured by the $C A B \mid$ review team.

\section{Author details}

${ }^{1} \mathrm{CABl}$, Nosworthy Way, Wallingford, Oxfordshire, United Kingdom. ${ }^{2}$ USDA, National Invasives Species Council, 1201 Eye Street, NW., 5th Floor,

Washington, DC, USA.

Received: 6 September 2012 Accepted: 20 February 2013

Published: 13 March 2013

\section{References}

1. Clavero M, GarcI-Berthou E: Invasive species are a leading cause of animal extinctions. Trends Ecol Evol 2005, 20(3):110.

2. Gurevitch J, Padilla DK: Are invasive species a major cause of extinctions? Trends Ecol Evol 2004, 19:470-474.

3. Miller RR, Williams JD, Williams JE: Extinctions of North American fishes during the past century. Fisheries 1989, 14:22-38.

4. Burbidge AA, Manly FJ: Mammal extinctions on Australian islands: causes and conservation implications. J Biogeogr 2002, 29:465-473.

5. Moher D, Cook DJ, Eastwood S, Olkin I, Rennie D, Stroup DF: Improving the quality of reports of meta-analysis of randomised controlled trials: the QUOROM statement - Review. Lancet 1999, 354:1896-1900.

6. McNeely JA, Mooney HA, Neville LE, Schei PJ, Waage JK: Global Strategy on Invasive Alien Species. Gland, Switzerland and Cambridge UK: IUCN; 2001.

7. Stevens A, Milne R: From The effectiveness revolution and public health. In Progress in Public Health. Edited by Scalley G. London: Royal Society for Medicine Press; 1997.

8. Pullin AS, Knight TM: Support for decision making in conservation practice: an evidence-based approach. J Nat Conserv 2003, 11(2):83-90.

doi:10.1186/2047-2382-2-5

Cite this article as: Roberts et al:: What is the evidence that invasive species are a significant contributor to the decline or loss of threatened species? A systematic review map. Environmental Evidence 2013 2:5.

\section{Submit your next manuscript to BioMed Central and take full advantage of:}

- Convenient online submission

- Thorough peer review

- No space constraints or color figure charges

- Immediate publication on acceptance

- Inclusion in PubMed, CAS, Scopus and Google Scholar

- Research which is freely available for redistribution 